\title{
Avaliação da ação da enzima alfa-amilase em efluente de arroz parboilizado
}

\author{
G. L. FERREIRA ${ }^{1}$, D. G. SANTOS ${ }^{1}$, F. MANZOLLI ${ }^{1}$, G. R. L. MENDES ${ }^{2}$ e P. J. S. FILHO ${ }^{1}$ \\ ${ }^{1}$ Instituto Federal Sul Rio-Grandense, curso de Engenharia Química \\ ${ }^{2}$ Universidade Federal de Pelotas, Programa de Pós-Graduação em Biotecnologia \\ E-mail para contato: grazilemos95@gmail.com
}

RESUMO - O processo de biorremediação consiste na degradação de contaminantes através de reações enzimáticas, resultando em substratos acessíveis para incorporação no metabolismo microbiano. Os cultivos das leveduras Pichia pastoris e Saccharomyces boulardii em efluente de arroz parboilizado obtiveram bons resultados de remoção e absorção do fósforo presente, porém necessita-se adicionar uma fonte extra de carbono. A composição dos componentes dos efluentes dos tanques de parboilização de arroz é desconhecida. Dessa forma, este trabalho buscou avaliar a ação da enzima alfa-amilase, a fim de elucidar a presença de resíduos de amido e facilitar o processo de assimilação dos substratos já existentes nesse efluente pela levedura Saccharomyces boulardii . A enzima alfa-amilase foi adicionada ao efluente previamente a fermentação. O pré-tratamento foi realizado em diferentes concentrações e tempo de ação, e as reações foram incubadas a $40^{\circ} \mathrm{C}$, sendo posteriormente realizada a fermentação das amostras das pré-tratadas e com um padrão (efluente sem adição de enzima e fontes extras de carbono). A avaliação da ação da enzima se deu pela análise da viabilidade celular da S. boulardii. Através da utilização da alfa-amilase verificou-se um melhor crescimento da levedura em comparação ao padrão, além disso, quanto maior concentração e o tempo de ação, melhor o crescimento da levedura. Dessa forma, sugere-se que há resíduos de amido passíveis de ação da enzima e posterior assimilação pela levedura.

\section{INTRODUÇÃO}

O Brasil está entre os dez maiores produtores de arroz do mundo. O arroz parboilizado representa $25 \%$ do consumo interno nacional e $50 \%$ do total de arroz exportado (ABIAP, 2011). O processo de parboilização de arroz é definido como sendo o processo hidrotérmico, no qual o arroz em casca é imerso em água potável com temperatura acima de $58^{\circ} \mathrm{C}$, seguido de uma gelatinização parcial ou total do amido e secagem (BRASIL, 1988). Devido a esse processo, ocorre a lixiviação de nutrientes presentes no arroz para água de encharque, gerando um efluente com grande Demanda Química de Oxigênio (DQO), fósforo e nitrogênio. Além disso, a falta de homogeneidade na distribuição da temperatura no processo de encharcamento resulta em uma maior lixiviação do material orgânico do grão, em especial do amido do endosperma (Queiroz e Koetz, 1997).

Apesar de o fósforo ser um componente essencial para os organismos, sendo utilizado na biossíntese de componentes celulares, seu descarte de forma incorreta na natureza pode ocasionar a eutrofização dos meios aquáticos. A utilização de leveduras como forma de tratamento de água residuais já vem sendo estudado desde 1990, primeiramente por Moriya et. al.(1990) e posteriormente por Chigusa et. al.(1996). A utilização de leveduras se deve ao 
fato de que estas apresentam em sua via de transdução de fosfato (PHO rota) proteínas responsáveis por armazenar fontes de fósforo do meio extracelular, no caso da levedura Saccharomyces cerevisae há pelo menos cinco tipos de proteína (Ogawa et. al, 2000).

Em biorreatores de escala laboratorial, a utilização da Saccharomyces cerevisae nos tratamentos de efluente de indústria de papel, fermentação ou com presença de corantes, se mostrou de grande eficácia devido a sua resistência a baixos $\mathrm{pHs}$, alta salinidade e alta índices de DQO (Yang et. al. 2011). Estudos recentes realizados com Pichia pastoris (Gil de los Santos et al. 2012) e Saccharomyces boulardii (Gaboardi 2015) em efluente de arroz parboilizado, demonstraram remoção de fósforo de $54 \%$ e $72 \%$, tendo sido necessário a adição de fontes extra de carbono, para que haja garantia de melhor crescimento da levedura.

A adição de fontes extras de carbono ocasiona um aumento inicial nos índices da DQO reduzindo a eficiência de remoção dos parâmetros ambientais. A ação de enzimas podem permitir a disponibilização de substratos passíveis de assimilação pela levedura através do seu metabolismo celular. A possível presença de fontes de amido oriundo do processo de encharmento do arroz parboilizado incentivou o presente estudo onde avaliou-se os efeitos da utilização da enzima alfa-amilase no efluente dos tanques de parboilização de arroz através do crescimento da levedura Saccharomycces boulardii nesse meio.

\section{MATERIAISE MÉTODOS}

\subsection{Micro-organismo}

Saccharomyces boulardii foi obtida de uma cápsula de Floratil®, pela reativação do liofilizado, cultivado em $10 \mathrm{~mL}$ de meio YM por $24 \mathrm{~h}$ a $150 \mathrm{rpm}$ e $28^{\circ} \mathrm{C}$. Após o cultivo, foi realizada a semeadura de uma gota da cultura em placas de YM sólido, e incubação por $48 \mathrm{~h}$ em estufa a $28^{\circ} \mathrm{C}$, para crescimento e isolamento das colônias. As placas foram mantidas sob refrigeração a $4{ }^{\circ} \mathrm{C}$ e repicadas a cada 15 dias.

\subsection{Determinação da ação enzimática}

\section{$\underline{\text { Enzimas }}$}

Nos experimentos foi utilizado enzima alfa-amilase do laboratório AG XXL (ação enzimática numa faixa de $15-55^{\circ} \mathrm{C}$ e $\mathrm{pH}$ de 4,5$)$.

Tempo de ação e concentração da enzima alfa-amilase

A enzima alfa-amilase foi adicionada no efluente seguindo um planejamento experimental DCCR $2^{2}$ com três pontos centrais para o teste das variáveis em três níveis de tempo de ação enzimática (2, 6 e $12 \mathrm{~min})$ e da concentração de enzima adicionada (5, 10 e 15 $\mathrm{UE} / \mathrm{L}$ de efluente). A temperatura foi mantida constante num banho-maria a $40{ }^{\circ} \mathrm{C}$ e o $\mathrm{pH}$ ajustado a 4,5 usando-se uma solução de $\mathrm{NaOH} 1 \mathrm{M}$.

A variável resposta do planejamento experimental foi a viabilidade celular da levedura cultivada no efluente previamente tratado com a enzima nos tempos e concentrações estabelecidos.

\subsection{Cultivo da Levedura}

$\underline{\text { Cultivo da levedura em banho-maria com agitação }}$ 
Os pré-inóculos e o inóculo de $S$. boulardii foram produzidos em meio YM (Yeast Medium, Difco, USA) num agitador orbital a $150 \mathrm{rpm}, 28{ }^{\circ} \mathrm{C}$ por 12 horas. Os cultivos foram realizados a $28^{\circ} \mathrm{C}$ por 48 horas usando-se $10 \%$ em volume de inóculo em balões aletados de $100 \mathrm{~mL}$ usando-se um volume útil de $20 \mathrm{~mL}$ de efluente de arroz parboilizado, sem esterilização, previamente tratado com as enzimas no tempo e concentração descritos anteriormente. Como parâmetro comparativo de controle da eficiência de disponibilidade foi efetuado um cultivo da levedura no efluente de arroz parboilizado sem o uso de enzima.

A viabilidade celular foi determinada ao longo do tempo por contagem de unidades formadoras de colônias (UFC $\mathrm{mL}^{-1}$ ) usando placas de YM sólido a $28^{\circ} \mathrm{C}$.

\subsection{Análise estatística}

$\mathrm{Na}$ análise estatística usou-se o software Statistix versão 7 (Analytica Software, Tallahassee, FL, USA). Os dados foram analisados por ANOVA (análise de variância) avaliando-se a influência dos fatores tempo, concentração e sua interação e a diferença de médias avaliadas pelo teste de Duncan $(\alpha<0,05)$, sendo a normalidade testada por ShapiroWilk.

\section{RESULTADOS E DISCUSSÃO}

Na Tabela 1 apresentam-se os resultados dos dados cinéticos do crescimento celular em UFC médio $\left(10^{5}\right.$ UFC.mL $\left.{ }^{-1}\right)$ da levedura Saccharoyces boulardii cultivada em efluente dos tanques de parboilização previamente tratados com a enzima alfa-amilase, ao de 24 horas de cultivo .

Tabela 1 - Contagem (média e desvio-padrão) de UFC da levedura Sacchoromyces boulardii cultivada em efluente de arroz parboilizado previamente tratados com enzima alfa-amilase.

\begin{tabular}{|c|c|c|c|c|c|c|c|c|}
\hline $\begin{array}{c}\text { Concentração } \\
(\mathrm{ppm})\end{array}$ & $\begin{array}{c}\text { Tempo } \\
(\mathrm{min})\end{array}$ & $0 \mathrm{~h}$ & $3 \mathrm{~h}$ & $6 \mathrm{~h}$ & $9 \mathrm{~h}$ & $12 \mathrm{~h}$ & $15 \mathrm{~h}$ & $24 \mathrm{~h}$ \\
\hline 5 & 2 & $\begin{array}{c}5,17 \\
\pm 1,06^{\mathrm{b}}\end{array}$ & $\begin{array}{c}15,07 \\
\pm 1,9^{\mathrm{a}}\end{array}$ & $\begin{array}{c}17,5 \\
\pm 3,53^{\mathrm{b}}\end{array}$ & $\begin{array}{c}44,00 \\
\pm 5,66^{\mathrm{b}}\end{array}$ & $\begin{array}{c}39,33 \\
\pm 3,06^{\mathrm{ab}}\end{array}$ & $\begin{array}{c}39,00 \\
\pm 7,81^{\mathrm{ab}}\end{array}$ & $\begin{array}{c}24,67 \\
\pm 10,12^{\mathrm{cd}}\end{array}$ \\
\hline 15 & 2 & $\begin{array}{c}7,87 \\
\pm 0,8^{\mathrm{b}}\end{array}$ & $\begin{array}{c}10,70 \\
\pm 0,3^{\mathrm{a}}\end{array}$ & $\begin{array}{c}11,00 \\
\pm 1,73^{\mathrm{b}}\end{array}$ & $\begin{array}{c}32,67 \\
\pm 13,2^{\mathrm{bc}}\end{array}$ & $\begin{array}{c}68,33 \\
\pm 6,66^{\mathrm{ab}}\end{array}$ & $\begin{array}{c}40,67 \\
\pm 1,15^{\mathrm{ab}}\end{array}$ & $\begin{array}{c}39,33 \\
\pm 2,0^{\mathrm{bc}}\end{array}$ \\
\hline 10 & 6 & 10,88 & 11,03 & 15,75 & 35,22 & 90,44 & 65,56 & 41,44 \\
$\pm 3,19^{\mathrm{b}}$ & $\pm 3,88^{\mathrm{a}}$ & $\pm 3,37^{\mathrm{b}}$ & $\pm 16,15^{\mathrm{b}}$ & $\pm 40,13^{\mathrm{a}}$ & $\pm 28,29^{\mathrm{a}}$ & $\pm 28,3^{\mathrm{b}}$ \\
\hline 5 & 12 & $\begin{array}{c}6,13 \\
\pm 2,49^{\mathrm{b}}\end{array}$ & $\begin{array}{c}10,80 \\
\pm 0,75^{\mathrm{a}}\end{array}$ & $\begin{array}{c}37,50 \\
\pm 3,54^{\mathrm{a}}\end{array}$ & $\begin{array}{c}53,00 \\
\pm 6,08^{\mathrm{ab}}\end{array}$ & $\begin{array}{c}43,33 \\
\pm 9,45^{\mathrm{ab}}\end{array}$ & $\begin{array}{c}46,33 \\
\pm 7,77^{\mathrm{ab}}\end{array}$ & $\begin{array}{c}28,00 \\
\pm 9,17^{\mathrm{bcd}}\end{array}$ \\
\hline 15 & 12 & 9,03 & 16,50 & 12,67 & 76,67 & 49,00 & 66,67 & 57,33 \\
$\pm 0,9^{\mathrm{b}}$ & $\pm 4,09^{\mathrm{a}}$ & $\pm 7,02^{\mathrm{b}}$ & $\pm 11,55^{\mathrm{a}}$ & $\pm 5,29^{\mathrm{ab}}$ & $\pm 5,77^{\mathrm{a}}$ & $\pm 12,5^{\mathrm{a}}$ \\
\hline & & $\begin{array}{c}60,00 \\
\pm 14,14^{\mathrm{a}}\end{array}$ & $\begin{array}{c}11,67 \\
\pm 4,72^{\mathrm{a}}\end{array}$ & $\begin{array}{c}19,67 \\
\pm 0,58^{\mathrm{b}}\end{array}$ & $\begin{array}{c}8,00 \\
\pm 1,41^{\mathrm{c}}\end{array}$ & $\begin{array}{c}12,00 \\
\pm 7,07^{\mathrm{b}}\end{array}$ & $\begin{array}{c}14,00 \\
\pm 2,82^{\mathrm{b}}\end{array}$ & $\begin{array}{c}11,00 \\
\pm 1,41^{\mathrm{d}}\end{array}$ \\
\hline
\end{tabular}

*as letras representam diferença estatística entre os tratamentos no mesmo tempo de cultivo para $\alpha<0,5$

** as letras representam diferença estatística na cinética de crescimento celular da levedura na mesma condição prévia do tratamento do efluente pela enzima para $\alpha<0,5$ 
Utilizando-se do teste de normalidade Shapiro Wilk, verificou-se que os pré-tratamentos e o padrão apresentam comportamento normal nos horários de $0,3,9$ e $24 \mathrm{~h}$ e tem diferença significativas entre si em relação a comparação de médias, apresentando o pré-tratamento melhores resultados no crescimento da levedura ao longo do tempo do cultivo realizado quando comparado com o padrão (efluente bruto).

Os resultados indicam que a concentração e o tempo de ação, isoladamente, influenciam diretamente nas quantidades de substratos desdobrados, apontando maiores concentrações e maiores tempos de reação, levam ao aumento das fontes biodisponíveis,. Contudo, a interação tempo $\mathrm{x}$ concentração não demonstrou efeito significativo $(\alpha<0,5)$.

A enzima alfa-amilase caracteriza-se por efetuar a catalise em substratos como glicogênio, amilose e amilopectina, efetuando a hidrólise das ligações $\alpha-1,4$ da amilose, amilopectina e glicogênio, liberando maltose e isomaltose (MOTTA, 2003). A maltose e a isomaltose são dissacarídeos formados por glicose, fonte energética passível de utilização para o crescimento da levedura $S$. boulardii. Nas amostras onde houve maior concentração enzimática e maior tempo de ação, demonstraram maior crescimento ao longo do tempo, sugerindo a presença de fontes desses tipos carboidrato no efluente e sua disponibilidade como metabólito da levedura.

$\mathrm{Na}$ amostra que foi pré-tratada com a concentração de $15 \mathrm{ppm}$ e tempo de ação de 12 minutos, verificou-se um crescimento de aproximadamente $9 \times 10^{5}$ para $4,9 \times 10^{6}$ no tempo de $12 \mathrm{~h}$, obtendo-se assim o crescimento de um log. Esse crescimento é similar ao obtidos por Gaboardi (2015), onde cultivos realizados em shaker com adição de $1 \%$ de sacacore os resultados de crescimento obtidos foram de $3 \times 10^{7}$ até $1,8 \times 10^{8}$ para $12 \mathrm{~h}$ e para cultivos realizados em YM teve a mesma faixa de crescimento ao de adição de sacarose. Além disso, Gaboardi (2015) teve um decaimento de crescimento no efluente bruto (sem adição de fontes extras de carbono) a partir das $9 \mathrm{~h}$, semelhante ao resultado obtido nesse estudo.

\section{CONCLUSÃO}

A ação hidrolítica da alfa-amilase disponibilizou fontes de carbono para o crescimento da levedura Saccharomyces boularddi no efluente de arroz parboilizado sendo os melhores resultados obtidos nos maiores tempos e concentração enzimática.

\section{REFERÊNCIAS}

ABIAP, ASSOCIAÇÃO BRASILEIRA DAS INDÚSTRIAS DE ARROZ PARBOILIZADO. Histórico da Associação. Disponível em: <http://www.abiap.com.br/sitept/content/conheca_abiap/historico.php>. Acessado em 22 de abril de 2017

BRASIL, MINISTÉRIO DA AGRICULTURA, SECRETARIA NACIONAL DE ABASTECIMENTO. Normas de identidade, qualidade, embalagem e apresentação do arroz. Brasília, v.8, n.20, p.1-25,1988.

Chigusa K., Hasegawa T., Yamamoto N., Watanabe Y., Treatment of wastewater from oil manufacturing plant by yeasts, Water Sci. Technol. 34 (1996) 51-58.

Gaboardi, G, "Produção do probiótico Saccharomyces boulardii em efluente de arroz parboilizado e avaliação da biorremediação". 63f. - Dissertação (Mestrado). Programa de 
Pós-Graduação em Biotecnologia. Universidade Federal de Pelotas. Centro de Desenvolvimento Tecnológico. Pelotas, 2015.

Santos D. G., Gil-Turnes, C., Conceição, F.R.. Bioremediation of parboiled rice effluent supplemented with biodiesel-derived glycerol using Pichia pastoris X-33. TheScientificWorldJournal. 2012 doi:10.1100/2012/492925

Moriya K., Iefuji H., Shimoi H., Sato S., Tadenuma M., Treatment of distillery wastewater discharged from beet molassesspirits production using yeast, J. Ferment. Bioeng. 69 (1990) $138-140$.

Motta, V. T. Bioquímica Clínica para Laboratório: Princípios e Interpretações. 4. ed. São Paulo: Robe Editorial, 2003

Ogawa N., DeRisi J. e Brown P. O. New Components of a System for Phosphate Accumulation and Polyphosphate Metabolism in Saccharomyces cerevisiae Revealed by Genomic Expression Analysis. Molecular Biology of the Cell. Vol. 11, 4309-4321, Dezembro 2000

Queiroz, M., Koetz, P.R., Caracterização do efluente da parboilização do arroz. Revista Brasileira de Agrociência. 3, 139-143, 1997.

Yang Q., Angly F. E., Wanga Z., Zhanga H. Wastewater treatment systems harbor specific and diverse yeast communities. Biochemical Engineering Journal 58- 59 (2011) 168- 176 